\title{
An experimental and parametric study on steel beams with web openings
}

\author{
Samadhan G. Morkhade ${ }^{1}$ Laxmikant M. Gupta ${ }^{1}$
}

Received: 21 October 2014 / Accepted: 4 July 2015/Published online: 21 July 2015

(c) The Author(s) 2015. This article is published with open access at Springerlink.com

\begin{abstract}
The use of steel beams with web openings (SBWOs) for structures such as industrial buildings and high-rise buildings has turned out to be extensive in recent times. There are numerous motives for which openings are kept. In this respect, an experimental investigation was planned and conducted on seven models of SBWOs. The initiative was to identify the maximum load behaviour, and deflection of steel beams with openings in the web. The performance of such beams has been considered only for vertical loads. Hot rolled steel beams of ISMB 100 with openings in the web were tested to failure. The beams were simply supported at the ends and subjected to a concentrated load applied at the mid-span. The openings considered in the experimental study are circular and rectangular only. All the beams were analysed by the finite element method by using general finite element analysis software ANSYS and the results were compared with those obtained experimentally. The test results found to be very useful for optimization of spacing-to-diameter ratio and aspect ratio of openings. The finite element results for deformation and ultimate strength shows good agreement with the corresponding values observed in the experiments. At last, a parametric study was carried out using finite element method to examine that which type of openings gives best performance during loading.
\end{abstract}

Keywords Steel beam with web openings (SBWOs) . Experimental study · Parametric study · Web post .

Samadhan G. Morkhade samadhanmorkhade@gmail.com

1 Department of Applied Mechanics, Visvesvaraya National Institute of Technology (VNIT), Nagpur 440 010, India
ANSYS · Ultimate load behaviour · Load-deflection behaviour $\cdot$ Finite element method

\section{Introduction}

Since 1940, numerous efforts have been made by structural engineers to find innovative ways to condense the cost of steel structures. Because of constraints on maximum permissible deflections, the high strength properties of structural steel cannot always be utilized to the best advantage. As a result, several new methods have been pointed, at increasing the stiffness of steel members without much increase in the weight of steel required.

Hence, SBWOs, i.e. castellated and cellular beams have been used extensively. Incorporation of services, such as hydraulic and ventilation pipes as well as electric cables, within the structural depth of the beams, see Fig. 1 is a major benefit in construction.

Researchers such as Bower (1968), Lawson (1987), Darwin (1990) have stated the presence of web openings may have big drawback on load-carrying capacity of structural members. However, the present design guides and specifications for such beams are either inadequate or difficult to use (SCI P355 2011). This may be due to the fact that the behaviour of I-Beams with web openings is complex to understand, analyse and difficult to simplify the design procedures. Therefore, it is imperative that more elaborate investigations are carried out to provide sufficient information to understand the behaviour so that a simple design method could be developed. A few experimental and analytical studies have been reported in the past regarding SBWOs. For steel beams with circular web openings, most of the design rules are applicable using an equivalent rectangular opening of modified dimensions, as 
Fig. 1 Reduction of beam depth by placing service incorporations in holes

Fig. 2 Beams specimen details with dial gauge and loading position
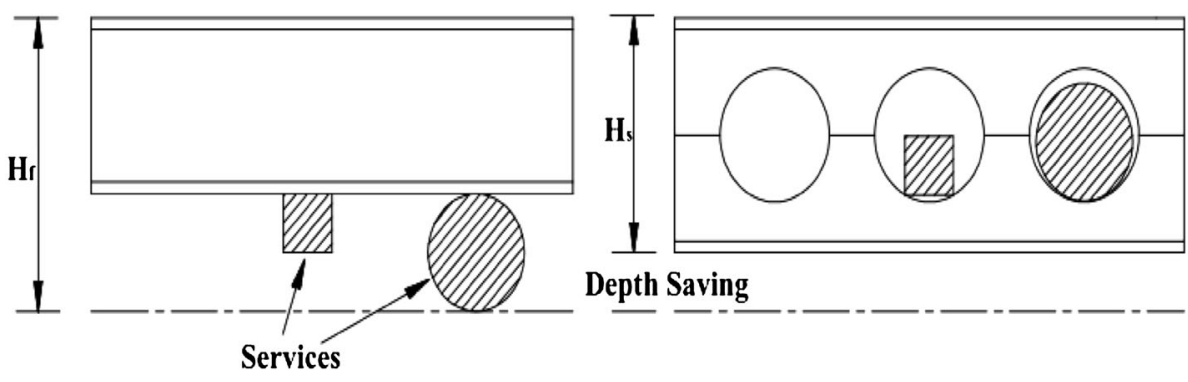

Depth Saving
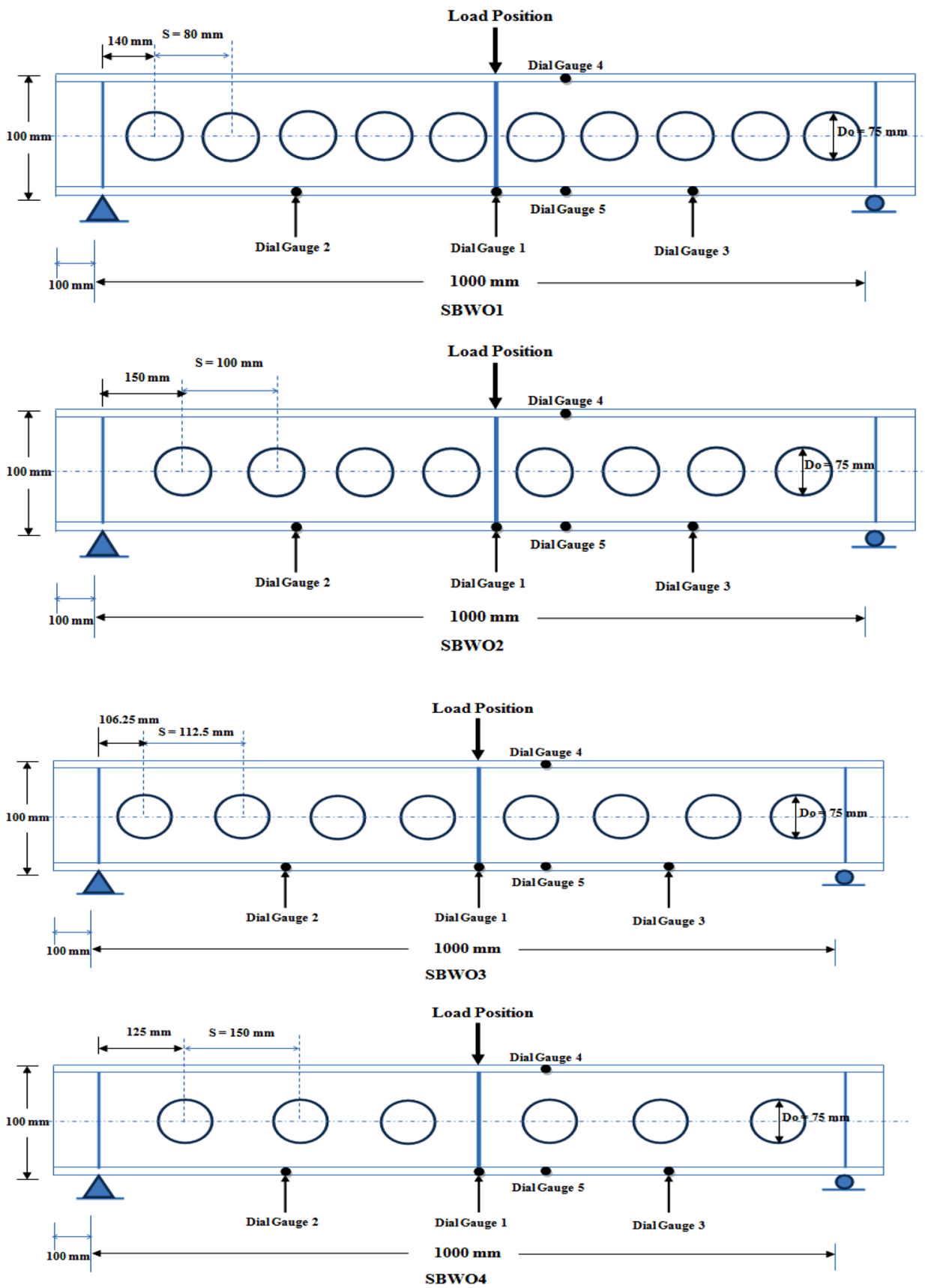
Fig. 2 continued
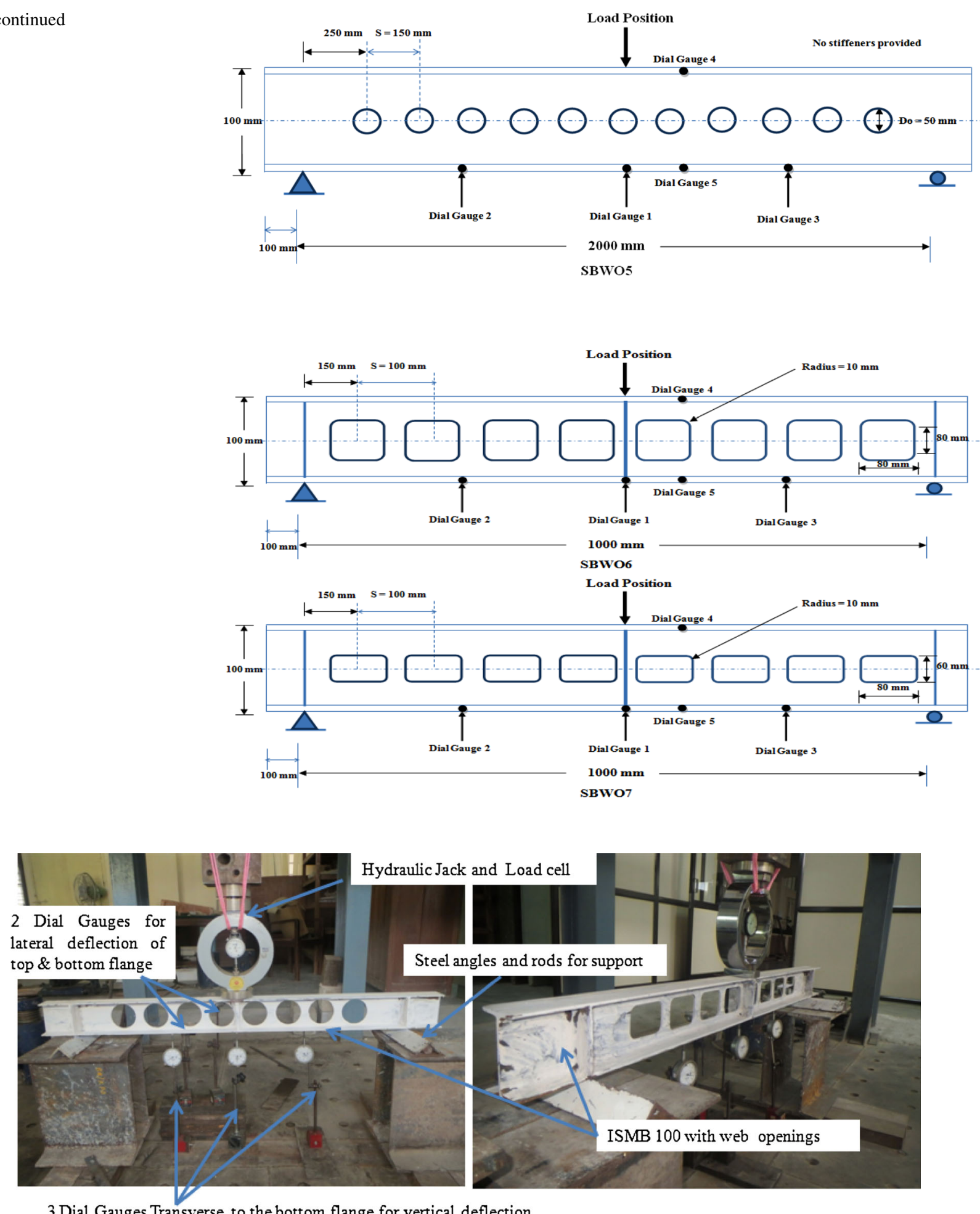

3 Dial Gauges Transverse to the bottom flange for vertical deflection

Fig. 3 Typical view of the experimental test setup

suggested by Redwood (1969). However, due to the simplistic approach, the load-carrying capacities of steel beams are always underestimated significantly. Elastic stress distribution in beams with large circular web openings has been examined by Chan and Redwood (1974) using the theory of elasticity and the curved beam analysis. To assess the load-carrying capacities of steel beams with several circular web openings in an explicit manner, a 
Table 1 Description of various beams

\begin{tabular}{lllll}
\hline Beams & Span of beams $(\mathrm{mm})$ & Type of openings & Spacing/diameter $\left(S / D_{\mathrm{o}}\right)$ & Aspect ratio $(L / D)$ \\
\hline SBWO1 & 1000 & Circular & 1.07 & - \\
SBWO2 & 1000 & Circular & 1.33 & - \\
SBWO3 & 1000 & Circular & 1.50 & - \\
SBWO4 & 1000 & Circular & 2.0 & - \\
SBWO5 & 2000 & Circular & 3.0 & - \\
SBWO6 & 1000 & Rectangular & - & 1 \\
SBWO7 & 1000 & Rectangular & - & 1.33 \\
\hline
\end{tabular}

design method (1990) based on the research works of Olander (1953) and Sahmel (1969) was developed at the Steel Construction Institute in 1990. The method was later incorporated into Amendment A2 of Euro code 3 (EN19931-3) Part 1.1: Annex N, in 1998 after minor modification. However, for steel beams with individual circular web openings, the use of a different set of approximate design rules was recommended in Annex N.

Thevendran and Shanmugan (1991) carried out laboratory tests and numerical study on steel beams with circular as well as rectangular openings. The models constructed by them were simply supported and cantilever beams made from a plexiglass sheet. Energy method was proposed to calculate the buckling load for such type of beams. Analytical study on steel beams with circular and rectangular openings has been reported by Chung and Lawson (2001) who employed a design method for composite beams with large web opening and is presented w.r.t Eurocode 4. Chung et al. (2001) suggested not only an empirical shear-moment interaction curve at the perforated section but also suggested a method for practical design of steel beams with circular web opening against Vierendeel mechanism. Chung et al. (2003) developed an empirical design method for steel beam with web openings of various sizes and shapes using generalized moment-shear interaction curve. The design method is fully presented in this paper supplemented with worked examples. Tsavdaridic and D'Mello (2011) investigated the effective 'strut' action of the web-post buckling and proposed an empirical formula which predicts the ultimate vertical shear load strength of web posts formed from the particular web opening shapes. An effort was made by Sweedan (2011) to develop a simplified approach to enable accurate prediction of a moment modification factor $K_{\mathrm{LB}}$ for cellular beam. Erdal and Saka (2013) performed an extensive experimental study and observed that failure modes found were lateral torsional buckling, Web-post buckling, Vierendeel bending and web buckling. More recently, Panedpojaman and Thepchatri (2013) performed a through finite element method by analysing 408 nonlinear finite element model and suggested a modified coefficient function which can be used to predict the deflection of cellular beams. Boissonnade et al. (2014) performed experimental and numerical study and suggested a design procedure of cellular beam against lateral torsional buckling.
Fig. 4 a Experimental setup of tensile test, $\mathbf{b}$ breaking of the specimen
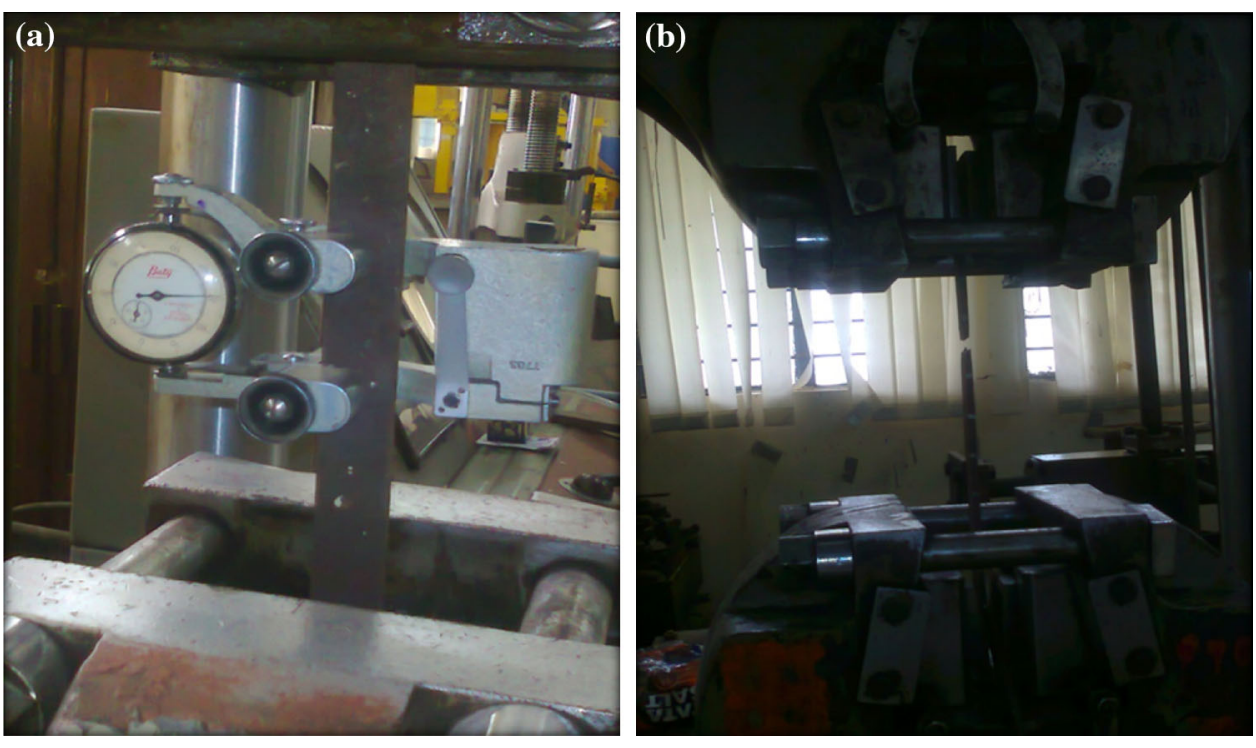
Table 2 Material properties of the test specimens

\begin{tabular}{llllll}
\hline Specimen & Actual width & Actual thickness & $\sigma y(\mathrm{MPa})$ & $\sigma u(\mathrm{MPa})$ & $E(\mathrm{MPa})$ \\
\hline Flange & & & & & \\
$\quad$ S1F & 20 & 5 & 376 & 487 & $1.98 \times 10^{5}$ \\
S2F & 22 & 5 & 352 & 495 & $2.10 \times 10^{5}$ \\
Overall average values & & 364 & 491 & $2.04 \times 10^{5}$ \\
Web & 20 & & & & \\
S1W & 4.7 & 322 & 450 & $1.96 \times 10^{5}$ \\
S2W & 4.7 & 337 & 430 & $2.01 \times 10^{5}$ \\
Overall average values & & & 329.5 & 440 & $1.99 \times 10^{5}$ \\
\hline
\end{tabular}

Considering all these factors, SBWOs (circular or rectangular) which is one of the suggested possible solutions for integration of technical utilities in buildings were tested up to failure. This study consists of tests on seven models of SBWOs subjected to vertical load as depicted in Figs. 2 and 3 . The present work is predominantly experimental oriented, and experiments have been performed on models up to failure. The details regarding the specification of beams like span, type of opening, etc. are given in the Table 1.

The information available on beams with web openings does not cover optimum spacing-to-diameter ratio and aspect ratio which should be adopted safely without webpost failure. The present study is, therefore, concerned with SBWOs with varying the spacing-to-diameter ratio and aspect ratio of openings. The dimension of openings such as diameter of openings, spacing of opening in case of circular openings and aspect ratio and fillet radius of corners in case of rectangular openings are taken from BS 5950 (2000) and SCI P355 (2011). An experimental study on such beams is described herein and the results from the experiment are compared with those obtained from finite element analysis. The object of this study is of twofold. First, the experimental results are used to calibrate the finite element modelling of SBWOs using finite element analysis software ANSYS version 12. Secondly, the test results are expected to provide an understanding of the behaviour of these beams in general. Shear-dominated failure in the web post controls the behaviour of these beams. Failure modes, load-deflection behaviour and ultimate load-carrying capacity are considered in the present investigation. Finally, a parametric study was performed to see that which type of opening gives well performance during the application of loading.

\section{Experimental programme}

\section{Experimental setup}

Steel beams with web openings with five different spacingto-diameter ratios (defined as the ratio of centre to centre
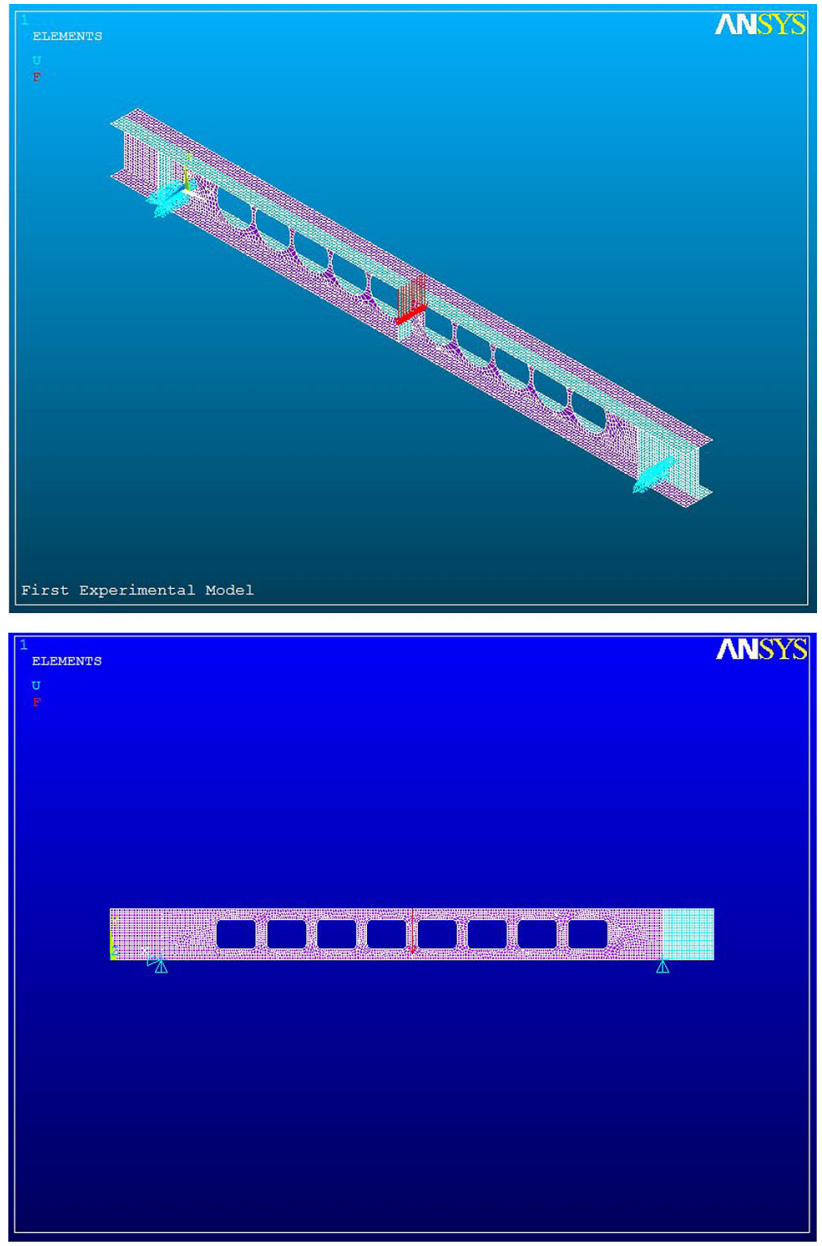

Fig. 5 FEM model of SBWOs

distance of openings to diameter of openings, $S / D_{\mathrm{o}}$ ) and two aspect ratios (defined as the ratio of length of opening to depth of opening) were tested to failure. The models tested for each category are mentioned in Table 1 . The details regarding position of proving ring, loading jack, and dial gauge are highlighted in Figs. 2 and 3. 'The other parameters such as dimensions and location of stiffeners, and the depth of the girder were kept constant to study the behaviour of web post exclusively. For all beams, overall 
Fig. 6 Shell element 181 geometry

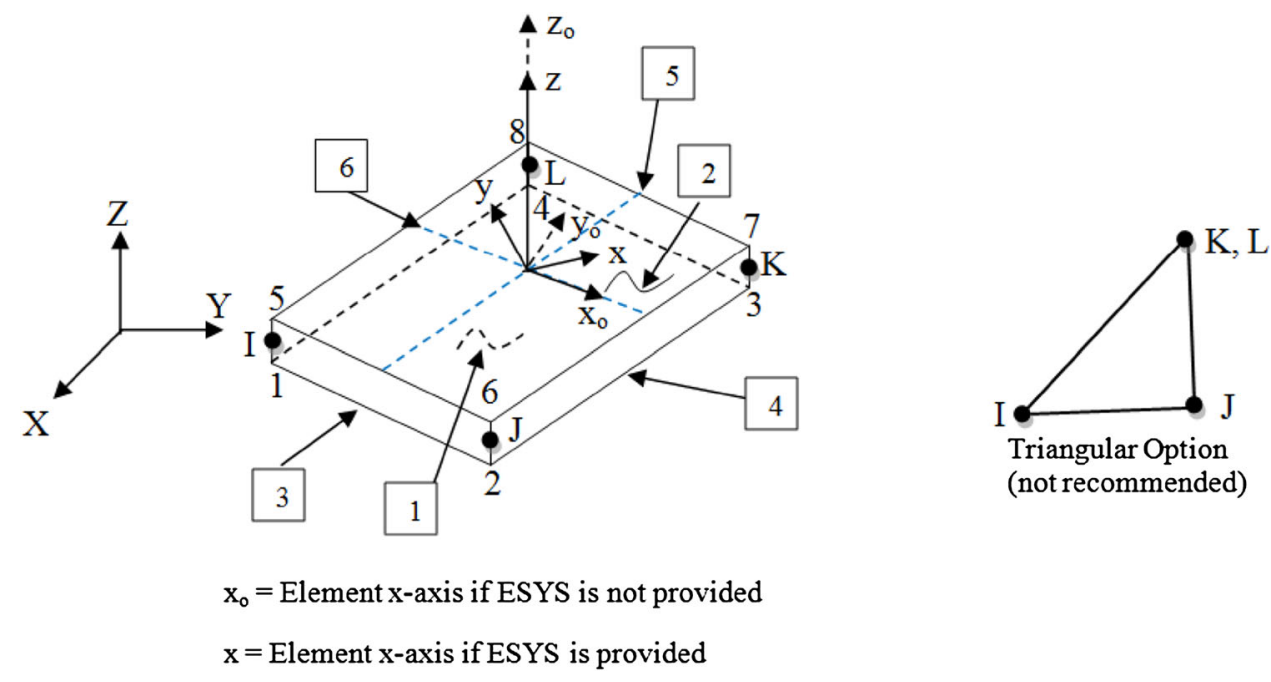

Table 3 Comparison of experimental and finite element ultimate load

\begin{tabular}{llllll}
\hline Specimen & Spacing/diameter $\left(S / D_{\mathrm{o}}\right)$ & Aspect/ratio $(L / D)$ & \multicolumn{2}{l}{ Ultimate load $\mathrm{Pu}(\mathrm{kN})$} & $\mathrm{Pu}$ \\
\cline { 5 - 6 } & & & $\mathrm{Pu}_{\text {Ansys }} / \mathrm{Pu}_{\text {Experimental }}$ & $\mathrm{Pu}_{\text {Exp. }}$ & \\
\hline SBWO1 & 1.07 & - & 09.00 & 14.25 & 0.63 \\
SBWO2 & 1.33 & - & 29.00 & 31.50 & 0.92 \\
SBWO3 & 1.5 & - & 30.00 & 31.00 & 0.96 \\
SBWO4 & 2.0 & - & 30.96 & 32.50 & 0.95 \\
SBWO5 & 3.0 & - & 15.98 & 16.50 & 0.96 \\
SBWO6 & - & 1 & 11.00 & 12.00 & 0.92 \\
SBWO7 & - & 1.33 & 17.90 & 18.50 & 0.97 \\
\hline
\end{tabular}

depth was maintained at $100 \mathrm{~mm}$ with nominal top and bottom flange width of $55 \mathrm{~mm}$ and the corresponding nominal thickness of flange $5 \mathrm{~mm}$ and that of web is $4.7 \mathrm{~mm}$. Transverse stiffeners were made of flat plates $25 \mathrm{~mm}$ wide and $5 \mathrm{~mm}$ nominal thickness. In the fifth model, the stiffeners were not provided, whereas in remaining all specimens the transverse stiffeners were provided at locations where concentrated forces are likely to occur, i.e. at centre of span and at supports, to prevent any modes of failure not required in the studies. All beams tested during experimental and numerical analysis have no lateral restrain, i.e. laterally unrestrained beams.

\section{Material properties}

Tensile test coupons cut from the flange and web plates of the section segments were tested to determine the material properties required for the numerical modelling of the beams with web openings. For all of the test specimens, only four tensile coupons, i.e. two from the flange plate and two from the web plate, were cut out for the material test, as all test specimens made from the same section. They were tested on Universal Testing Machine of $500 \mathrm{kN}$ capacity, Ref. Fig. 4 at material testing laboratory of Visvesvaraya

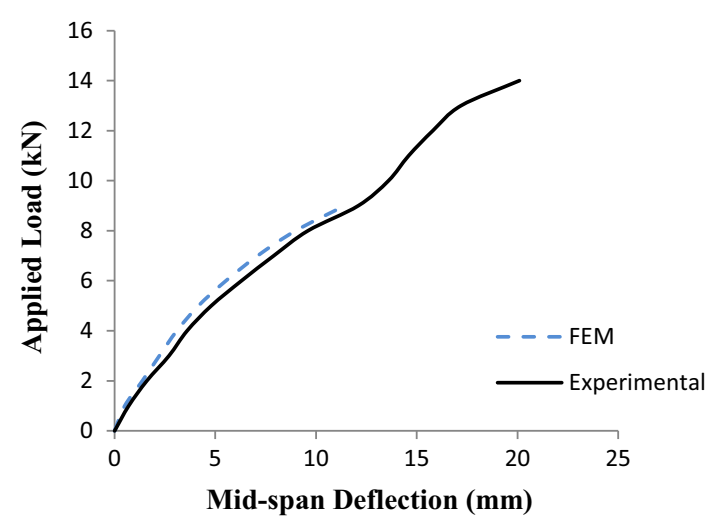

Fig. 7 Load versus mid-span deflection graph for SBWO1

National Institute of Technology, Nagpur, India. The results, yield stress, ultimate stress and modulus of elasticity obtained from the coupon tests are given in Table 2 .

\section{Fabrication of the test specimens}

Hot rolled steel beams of Grade E250 (Fe 410W) that complied with IS 2062 (2006) "Specification of Steel for General Structural Purposes" were used to fabricate all test specimens. 


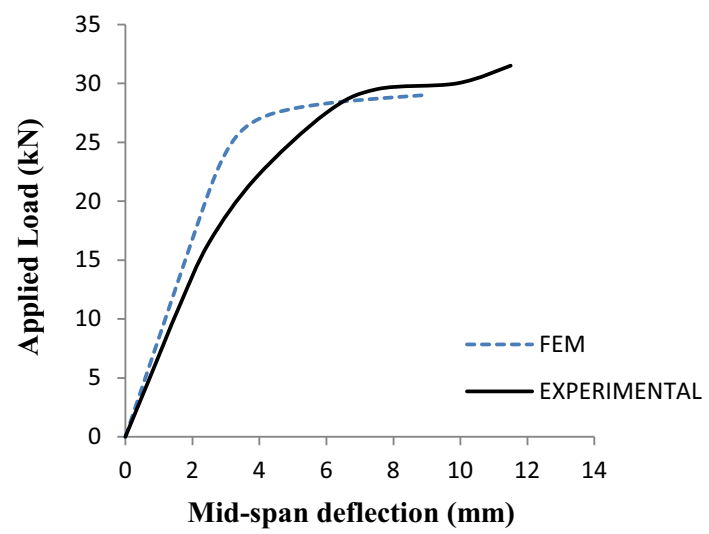

Fig. 8 Load versus mid-span deflection graph for SBWO2

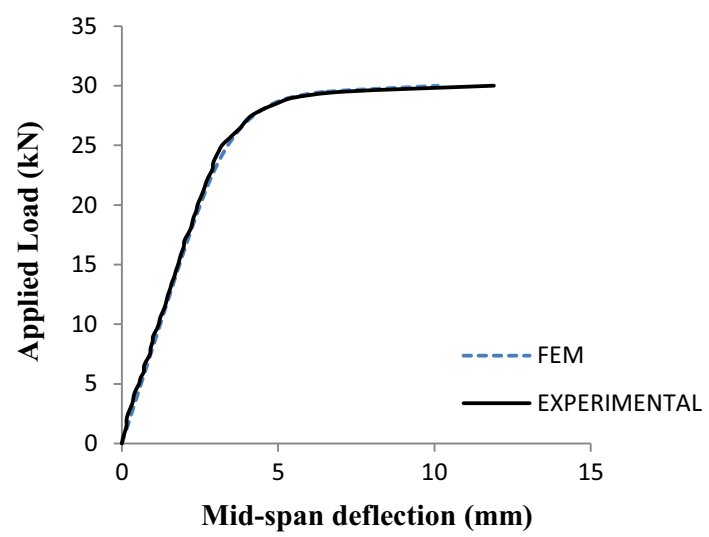

Fig. 9 Load versus mid-span deflection graph for SBWO3

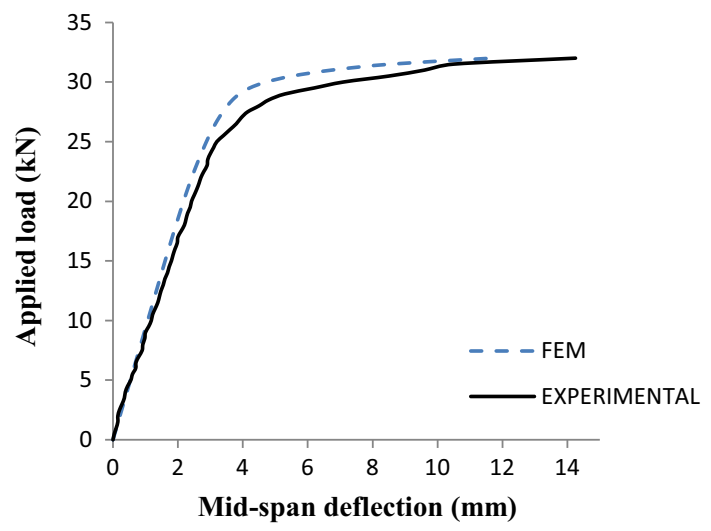

Fig. 10 Load versus mid-span deflection graph for SBWO4

Fabrication was carried out in accordance with the design of openings. The basis regarding the spacing-to-diameter ratio $\left(S / D_{\mathrm{o}}=1.08-1.5\right)$ is taken from BS 5950 part-I (2000). The openings were cut from a web plate by means of drilling with utmost care to get a required accuracy. The welding was totally eliminated for making openings as it affects the

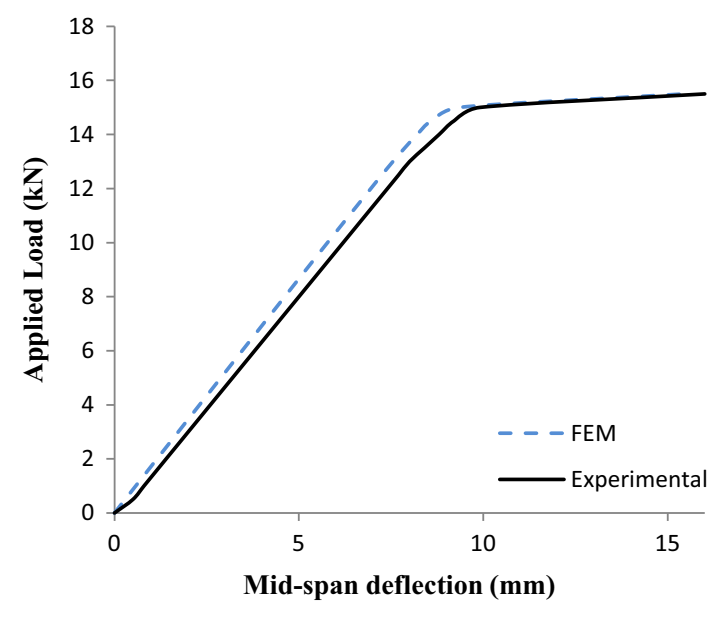

Fig. 11 Load versus mid-span deflection graph for SBWO5

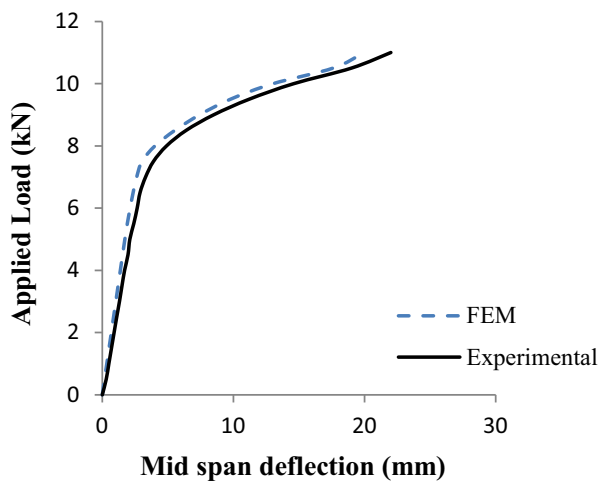

Fig. 12 Load versus mid-span deflection graph for SBWO6

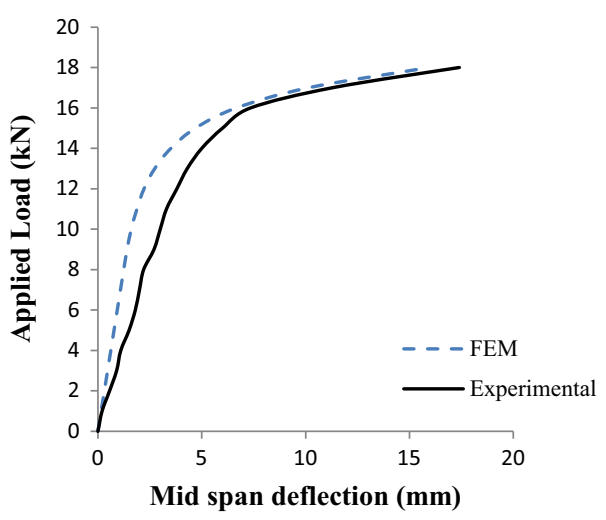

Fig. 13 Load versus mid-span deflection graph for SBWO7

properties of steel due to heating process. Once all the openings were cut from web plate, then welding of stiffeners was carried out on either side of the web. Sufficient care was taken to minimize the welding distortion in the web plate. The models were white wash by means of lime in order to identify the yielded and stress concentration zone properly. The reason 
is that as the yielding occurs, the dry lime falls down from the sections and identification of stress concentration zone becomes easier.

\section{Test procedure}

The beam having simply supported boundary conditions was set up in the loading frame with sufficient care taken to ensure that the specimen was correctly positioned in the loading frame and the midpoint of the beam was in line with the centre line of the loading hydraulic jack. The
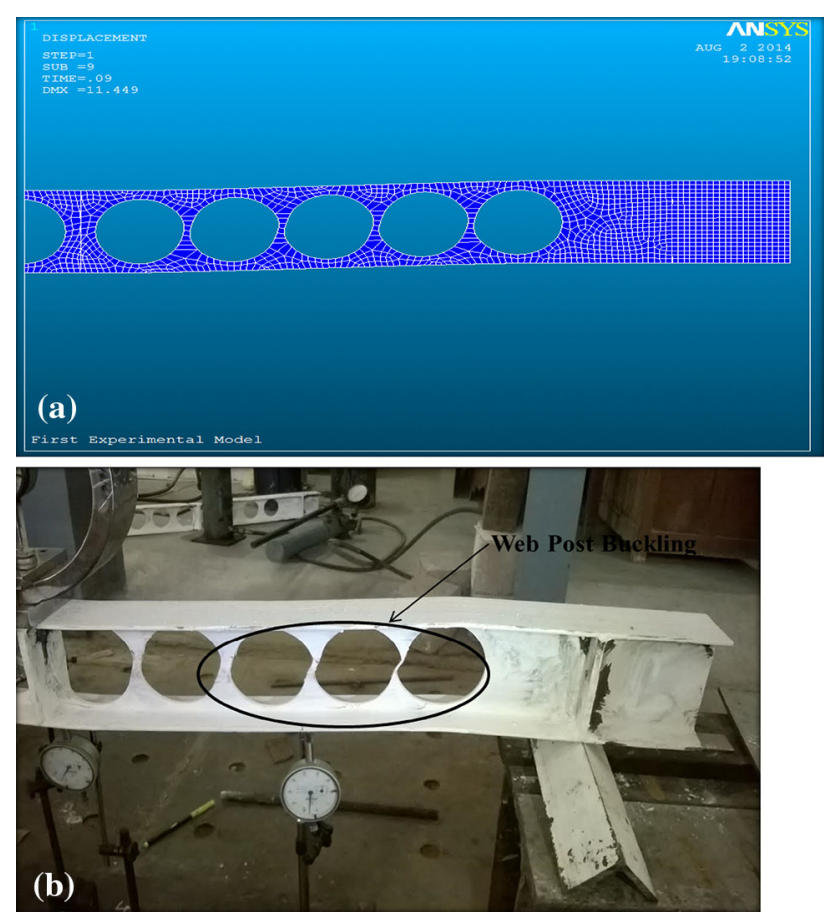

Fig. 14 Comparison of deformed shaped of the beam SBWO1 a FEM, b experimental specimen was heavily gauged, as shown in Fig. 2, in an attempt to identify a primary mode of failure, i.e. either buckling load for the web post, the formation of plastic hinges, or local buckling of the flange. Prior to application of load on the specimen, all the dial gauges were calibrated properly. Before the actual test, a small preload not exceeding $5 \%$ of the expected ultimate load was applied slowly and removed to eliminate any slack in the support system so that the specimen would be properly seated on the supports. The loading and unloading process was repeated a few times and this procedure also helped to check whether the dial gauges functioned properly. Readings were initialised after ensuring that all instruments worked satisfactorily. The specimen was loaded first up to $20 \%$ of the expected failure load and then unloaded to zero value. It was observed that the deflection readings reached the initial values when unloaded. The procedure was repeated up to $35 \%$ of the expected failure load and the specimen was finally loaded to failure by increasing the load gradually by a predetermined increment. The five dial gauges were installed, three for measurement of vertical deflection placed at $\mathrm{L} / 4, \mathrm{~L} / 2$ and $3 \mathrm{~L} / 4$, respectively, and two for measurement of lateral deflection of top and bottom flange, respectively, as shown in Fig. 2. The beam was then tested to failure. After the maximum load was attained and unloading occurred with increase in beam deflection, the load was then removed. The ultimate load and the mode of failure for each of the specimens were noted. The same test procedure was adopted for all the specimens.

\section{Finite element analysis}

The objective of this section is to carry out nonlinear finite element analysis of the SBWOs that were considered in the experimental study to determine their ultimate load-
Fig. 15 Stress concentration around the corners of rectangular openings SBWO6. a Experimental, b analytical

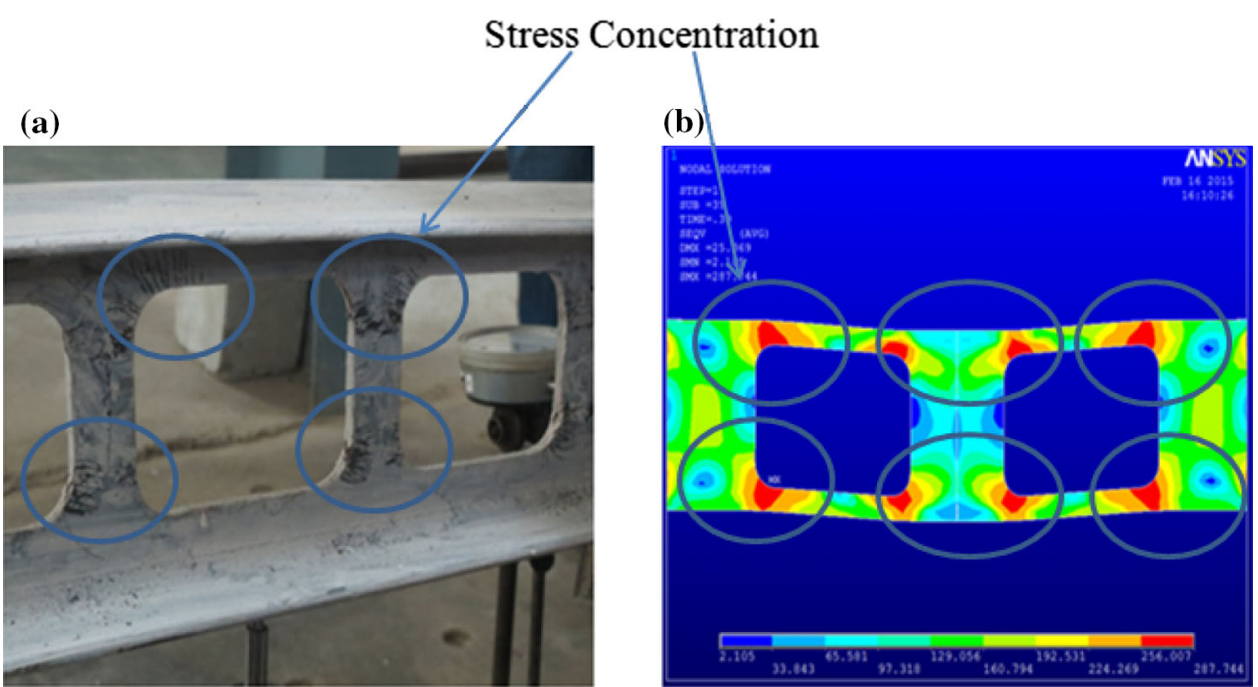




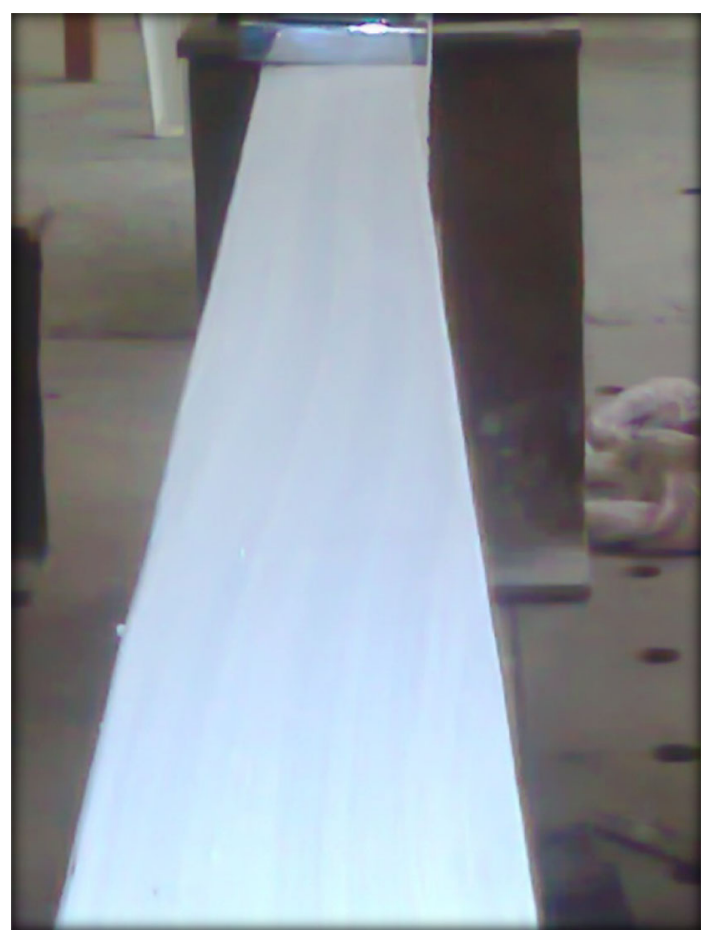

Fig. 16 Lateral movement of beam SBWO5 (lateral torsional buckling)

carrying capacity for comparison. The finite element method has been used to predict their entire response to increasing values of external loading until they lose their load-carrying capacity. These finite element models are used to simulate the experimental work to verify the test results and to investigate the nonlinear behaviour of failure modes such as web-post buckling, shear buckling and Vierendeel bending of SBWOs. A 3-D finite element model is developed to simulate the behaviour of steel beam with web openings having an I-shaped cross section using the finite element package ANSYS v12, which incorporated material as well as geometric nonlinearity in beam model. The material properties as given in the Table 2 are used in the analysis. A bilinear stress-strain curve was used in material modelling of steel together with the von Mises yield criterion and the kinematic hardening rule, which is suitable for steel. The large deformation effects have been considered in the analysis. Figure 5 shows the finite element model of steel beams with circular and rectangular web openings. In the present study, four noded shell 181 element with reduced integration points having six degrees of freedom per node is used, see Fig. 6. Nonlinear finite element models of these steel beams with web opening specimens are built to determine maximum values and locations of stress, strain and displacement concentrations under point loading. The objective of these analyses is to determine ultimate load, stress, strain and displacement in the steel beam with web openings and to compare experimental results with the results of observed nonlinear finite element analysis.
Fig. 17 Various types of web opening
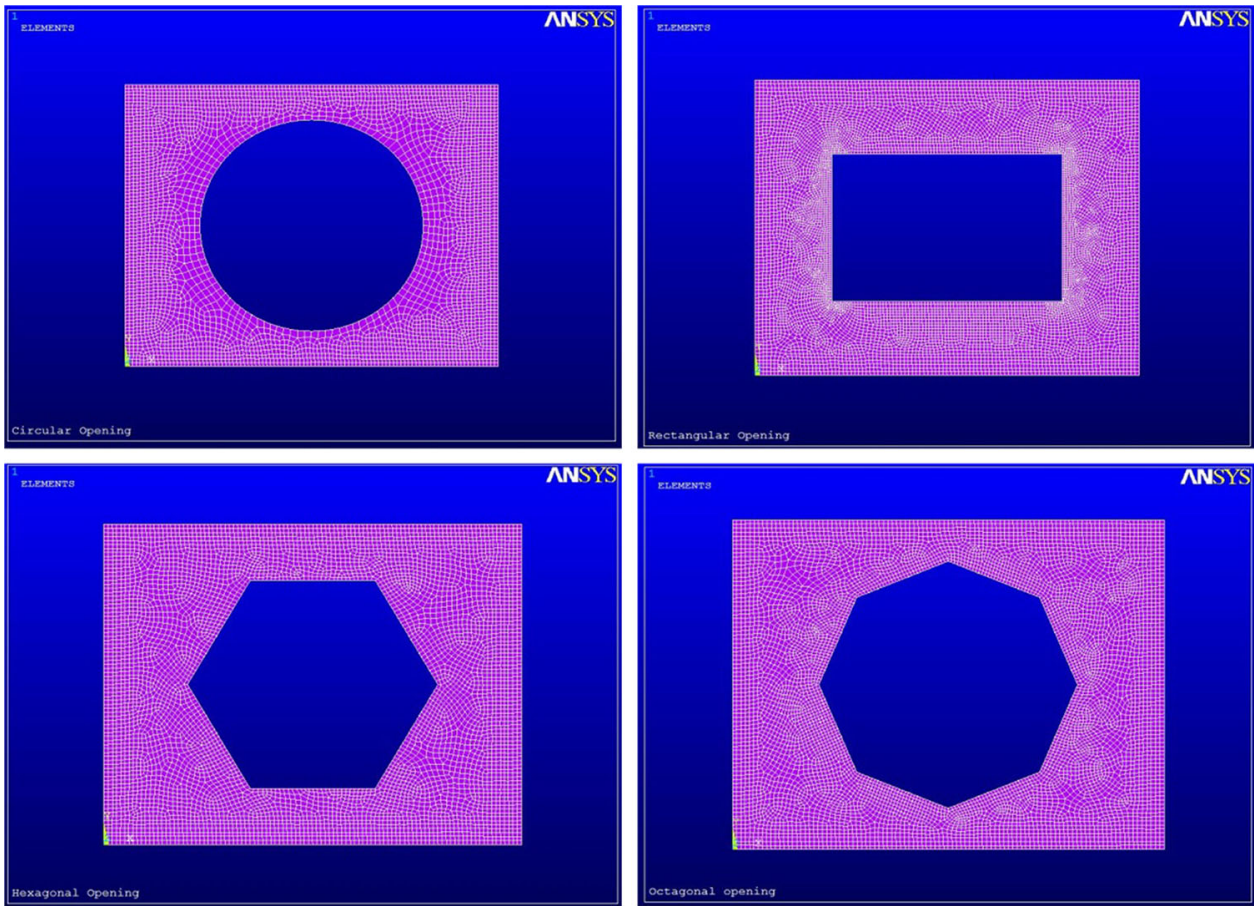


\section{Results and discussion}

The values of ultimate loads obtained from the experiments and finite element analysis are presented along with the comparison between the two values for all beams in Table 3. Variations of mid-span deflection with the applied load for typical beams are shown in Figs. 7, 8, 9, 10, 11, 12 and 13. It has been observed from the experiments that stiffness and ultimate load of the steel beam with web openings decrease with an increase in the opening area (i.e. decrease in the $S / D_{\mathrm{o}}$ ratio). Comparison between the ultimate loads obtained experimentally and those predicted by the finite element modelling presented in Table 3 shows that the finite element solutions are relatively close to the corresponding experimental results. It can, therefore, be concluded that ANSYS analysis is reliable in predicting the ultimate strength of SBWOs. Comparisons between experimental and finite element load-deflection curves shown in Figs. 7, 8, 9, 10, 11, 12 and 13 show a satisfactory agreement between the analytical and experimental curves.

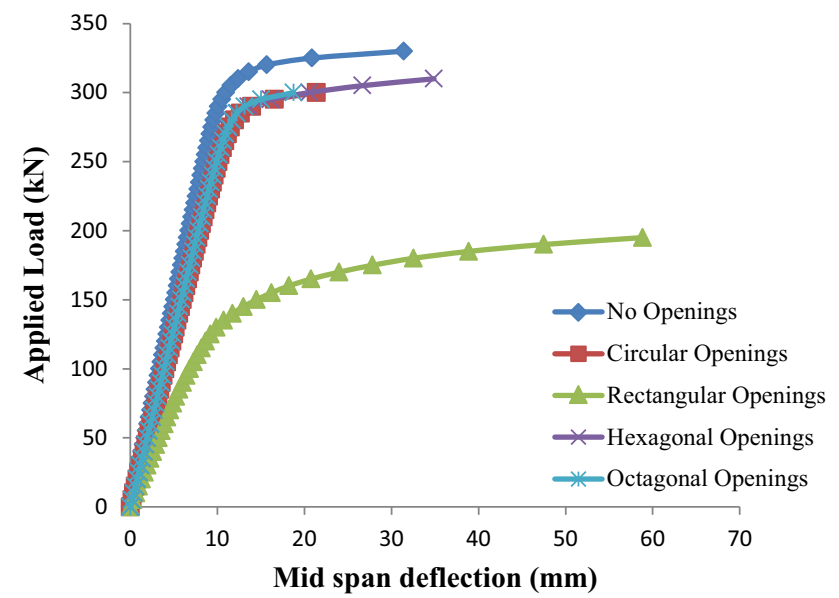

Fig. 18 Load versus mid-span deflection graph for diameter $0.50 d$

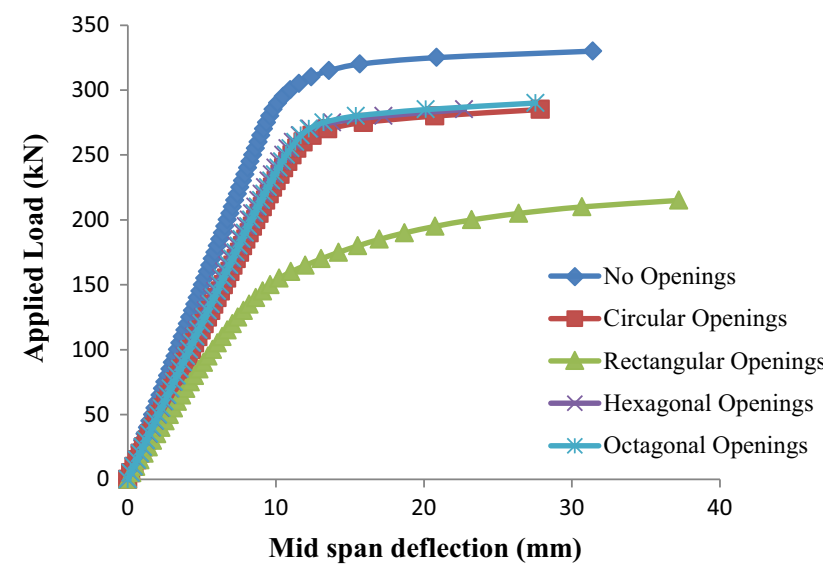

Fig. 19 Load versus mid-span deflection graph for diameter $0.62 d$
It is clear from the figures that the experimental and finite element results are close in most beams except SBWO1 in which the two curves do not match well. The discrepancy between the two curves might be due to the inability of the ANSYS program. The main reasons which are responsible for difference in experimental and numerical failure loads is mainly due to human error in experimental work, variation of material properties and stiffness of member. The stiffening behaviour in some specimens (SBWO1, 2, 6, 7) has not been observed in numerical analysis because the stiffness of stiffener provided at centre in specimens is very high. Figure 14 shows the deformed shapes found in experimental and finite element studies for SBWO1. Rectangular openings were found to be very critical as they show very high stress concentration around the corner regions of openings as shown in Fig. 15. Figure 16 shows the small lateral deflection observed during the testing of fifth model (SBWO5).

\section{Parametric study}

Having established the accuracy of the finite element method to predict the load-carrying capacity, a parametric study was carried out to assess the effect of various parameters on the behaviour of steel beams with various types of web openings. Here an attempt is made to see the performance of few types of web openings such as circular, rectangular, hexagonal and octagonal. Simply supported beam of ISMB 400 of span $4 \mathrm{~m}$ subjected to concentrated load at top flange and material properties as given in Table 2 are considered in the study. Load-bearing stiffeners are provided under concentrated load and at supports to avoid any premature failure in the analysis. In case of rectangular openings, a fillet of radius $20 \mathrm{~mm}$ is provided to corners to avoid high stress concentrations in those

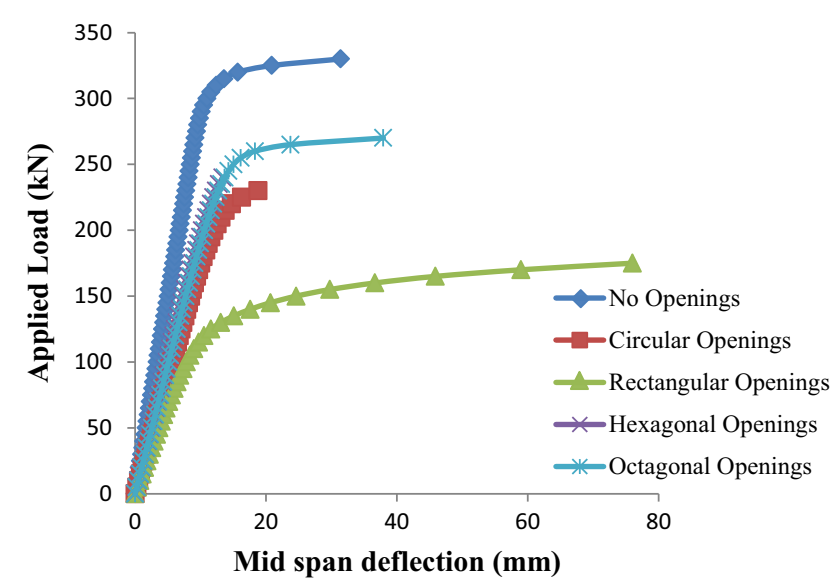

Fig. 20 Load versus mid-span deflection graph for diameter $0.75 d$ 
regions. Figure 17 shows the various types of openings modelled in ANSYS. The diameters considered in the study are $0.5 d, 0.62 d$ and $0.75 d$. The area of each opening is almost kept same. Figures 18, 19 and 20 show the load versus mid-span deflection graph for the openings considered in the study.

\section{Conclusions}

The purpose of this study was to evaluate the strength of steel beam with web openings; therefore, numbers of experiments are carried out on SBWOs; all those are described and presented here. Beams with different web openings' configurations and web opening area have been tested until failure. Based on the results of the investigation, the following findings and conclusions are made.

- Test results show that the ultimate load-carrying capacity and the stiffness decrease with increase in opening area. Failure modes were found same for all the beams with web openings.

- A comparison of the experimental and analytical results shows that the finite element analysis using the ANSYS software is capable of predicting the elastic and ultimate load behaviour of SBWOs up to reasonable degree of accuracy. The load-deflection curves obtained by finite element analysis in ANSYS also match with results of the experiments.

- The minimum limit given by BS 5950 on $S / D_{\mathrm{o}}$ is 1.08 which was found to be critical. The $S / D_{\mathrm{o}}$ ratios of 1.33 and 1.5 were found to be very effective. $S / D_{\mathrm{o}}$ ratio of 3 was found to be very conservative, if the openings are provided as per this ratio; the response of beam is almost similar to that of plain-webbed beam.

- Circular web openings were found to be very effective in all respects, like it shows a very less stress concentration at the web openings, easy to fabricate and architectural appearance, etc.

- Rectangular openings were found to be very critical as they show very high stress concentration around the corner regions. It is also seen that the deformations of the rectangular openings are large compared to the other type of web openings. The rectangular web openings of $0.75 d$ have a very high stress intensity compared to the other depth of openings such as $0.62 d$ and $0.50 d$.

- Though structural performance of hexagonal and octagonal openings is found to be similar, hexagonal openings have good architectural view and are easy for fabrication.
However, with the limited number of tests carried on various beams, the researcher's counsel advance testing to increase the record for steel beam with web openings.

Open Access This article is distributed under the terms of the Creative Commons Attribution 4.0 International License (http://crea tivecommons.org/licenses/by/4.0/), which permits unrestricted use, distribution, and reproduction in any medium, provided you give appropriate credit to the original author(s) and the source, provide a link to the Creative Commons license, and indicate if changes were made.

\section{References}

ANSYS version 12.0, Inc., Canonsburg, 2009

Boissonnade N, Nseir J, Lo M, Somja H (2014) Design of cellular beams against lateral torsional buckling. Proc Inst Civil Eng Struct Build 167:436-444

Bower JE (1968) Design of beam with web openings. J Struct Div 94(3):783-807

BS 5950: Part 1 (2000) Structural use of steelwork in building. British Standards Institution, London: Code of practice for design. Rolled and welded sections

Chan PW, Redwood RG (1974) Stresses in beams with circular eccentric web holes. J Struct Div 100(ST1):231-248

Chung KF, Lawson RM (2001) Simplified design of composite beams with large web openings to Euro code 4. J Constr Steel Res $57: 135-163$

Chung KF, Liu TCH, Ko ACH (2001) Investigation on Vierendeel mechanism in steel beams with circular web openings. J Constr Steel Res 57:467-490

Chung KF, Liu TCH, Ko ACH (2003) Steel beams with large web openings of various shapes and sizes: an empirical design method using a generalized moment-shear interaction curve. J Constr Steel Res 59:1177-1200

Darwin D (1990) Steel and composite beams with web openings. Steel design guide series no. 2. AISC, Chicago

Design of composite beams with large web openings. SCI P355 (2011)

Erdal F, Saka MP (2013) Ultimate load carrying capacity of optimally designed steel cellular beams. J Constr Steel Res 80:355-368

European committee for standardization. EN 1993-1-3, Euro code 3 (EC3) (1998) Design of steel structures-part 1.1: general rules and rules for buildings; 1992, and amendment A2 of Euro code 3: Annex N 'Openings in webs'. British Standards Institution

IS 2062 (2006) Specification of steel for general structural purposes

Lawson RM (1987) Design for openings in the webs of composite beams. CIRIA Special Publication and SCI Publication 068. CIRIA/Steel Construction Institute, London

Olander HC (1953) A method of calculating stress in rigid frame corners. J Struct Div Proc. ASCE

Panedpojaman P, Thepchatri T (2013) Finite element investigation on deflection of cellular beams with various configuration. Int $\mathbf{J}$ Steel Struct 13:487-494

Redwood RG (1969) The strength of steel beams with unreinforced web holes. Civil Eng Public Works Rev 64(755):559-562

Sahmel P (1969) Konstruktive Ausbildung und Näherungsbenechaung geschewisster Biegeträger und Torsionsst äbe mit grossen stegausnehmungen [The design, construction and approximate analysis of weld beams and torsion members having large web openings]. Schweissen und Schneiden 21(3):116-122

Sweedan AMI (2011) Elastic lateral stability of I-shaped cellular steel beams. J Constr Steel Res 67:151-163 
Thevendran V, Shanmugam NE (1991) Lateral buckling of doubly symmetric beams containing openings. J Eng Mech 117(7): $1427-1441$

Tsavdaridis KD, D'Mello C (2011) Web buckling study of the behaviour and strength of perforated steel beams with different novel web opening shapes. J Constr Steel Res 67: $1605-1620$

Ward JK (1990) Design of composite and non-composite cellular beams. The Steel Construction Institute 